\title{
Método de avaliação global de desempenho higrotérmico de habitações de interesse social para Porto Alegre - RS - Brasil
}

\author{
Method for global evaluation of the hygrothermal \\ performance of low-cost housing in Porto Alegre - RS - \\ Brazil
}

\section{Giane de Campos Grigoletti Miguel Aloysio Sattler}

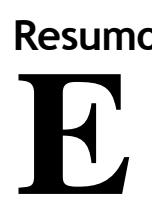

ste artigo apresenta uma proposta de método de avaliação global de desempenho higrotérmico de habitações térreas unifamiliares de interesse social para o clima de Porto Alegre, RS, mediante requisitos e critérios de fácil aplicação pelos profissionais envolvidos neste tipo de empreendimento, que complementa as normas de desempenho brasileira recém aprovadas. Os parâmetros foram obtidos da literatura e incluem coeficientes volumétricos globais de perda e ganho de calor, categoria de inércia e efusividade térmica, entre outros. Valores de referência para os parâmetros foram definidos a partir de normas brasileiras e da análise de quatro habitações, duas delas submetidas a medições in loco, consideradas como típicas para a região. O método foi submetido à opinião de agentes locais ligados ao financiamento, projeto, execução e avaliação de habitações e de especialistas em conforto térmico de instituições de ensino e pesquisa. São indicados dezessete parâmetros para avaliação e três classificações possíveis, considerando a disponibilidade de recursos nos órgãos governamentais. Os resultados apontaram a pouca variação entre as habitações analisadas quanto à efusividade térmica, e confirmaram a importância da cobertura para o desempenho térmico das edificações térreas.

Giane de Campos Grigoletti

Centro de Tecnologia Universidade Federal de Santa

Maria, Campus Camobi

Av. Roraima, 1000, Cidade Universitária, Bairro Camobi

Santa Maria - RS - Brasil CEP $97105-900$

Tel.: (55) 3220-8771 E-mail:

grigoletti@smail.ufsm.br

Miguel Aloysio Sattler Núcleo Orientado para Inovação da Edificação
Universidade Federal do Rio Grande do Sul

Av. Osvaldo Aranha, 99, $3^{\circ}$ andar, Centro

Porto Alegre - RS - Brasil CEP $90035-190$

Tel.: (55) $3316-3900$

E-mail: masattler@gmail.com

Recebido em 12/02/2010

Aceito em 23/04/2010
Palavras-chave: Desempenho higrotérmico. Habitação de interesse social. Avaliação de desempenho.

\section{Abstract}

This paper proposes a method for the evaluation of the global thermal of low-cost single-family one-floor dwellings, considering the climate of Porto Alegre, Brazil. This method uses requirements and criteria that are easy to apply by professionals involved in this type of project, which complement the recently approved Brazilian building performance standards. The thermal parameters were obtained from the literature and include global heat flow coefficients, thermal inertia and effusivity, among others. Reference values were obtained from Brazilian standards and through the thermal analysis of four dwellings, two of them submitted to in situ measurements, considered as typical in the context of the region. The method was submitted to the evaluation of representatives of local governmental organizations involved in the design, financing, building, and evaluation of low-cost housing as well as by experts from Brazilian research and teaching institutions. Seventeen parameters for evaluation and three degrees of performance were defined, in accordance to availability of government resources. The findings indicate that the variation of thermal effusivity among the dwellings was very low, and confirmed the importance of roofs for the performance of one-floor houses.

Keywords: Hygrothermal performance. Low-cost housing. Performance evaluation. 


\section{Introdução}

Recentemente, no Brasil, um conjunto de normas foi aprovado com o objetivo de definir requisitos e critérios de desempenho térmico para habitações de interesse social (HIS) com até três pavimentos e para edifícios habitacionais de até cinco pavimentos (ABNT, 2005, 2008), sendo um importante passo para a normalização do desempenho térmico de HIS no Brasil.

A ABNT (2005, 2008) recomenda métodos padronizados para cálculo de variáveis arquitetônicas, procedimentos para tratamento de dados climáticos, zoneamento bioclimático, metodologia de avaliação e diretrizes construtivas para HIS no Brasil. As normas especificam procedimentos para cálculo de resistência térmica, transmitância térmica, capacidade térmica, atraso térmico e fator de calor solar de componentes da envolvente da edificação, e apresentam o Zoneamento Bioclimático Brasileiro, que é a base para a definição de um conjunto de recomendações e estratégias construtivas destinadas a HIS. Embora um passo importante para a melhoria do desempenho térmico de edificações, as normas detêm-se em paredes e coberturas, e não na edificação como um todo. Essa análise isolada pode não expressar o comportamento térmico real dela.

Outra proposta, desenvolvida por Turik (1988), envolve a análise de temperaturas superficiais internas, pressão de vapor no interior dos fechamentos, heterogeneidade das temperaturas superficiais internas, diferença entre as temperaturas ambientais médias orientadas e outros requisitos qualitativos, além de usar a equação de balanço térmico da edificação para análise do coeficiente global de perdas e ganhos térmicos. Essa proposta é mais completa do que o conjunto de normas NBR 15220 (ABNT, 2005) e NBR 15575 (ABNT, 2008), pois inclui o efeito provocado pela proporção entre os diferentes tipos de fechamentos (portas, alvenarias, etc.), bem como características específicas da ventilação dos cômodos, o que torna a análise mais profunda.

Barbosa (1997) propõe a comparação das horas de desconforto térmico promovidas por determinado sistema construtivo com as horas de desconforto térmico consideradas aceitáveis para o referencial cultural assumido. A abordagem da autora, ao relacionar o nível de satisfação dos usuários com o ambiente térmico interno ao desempenho térmico da edificação, está sujeita a variações temporais e espaciais, pois a tolerância das pessoas é mutável e difícil de determinar. Haveria necessidade de se fazer uma análise de tolerância em uma amostra mais significativa, para delimitar as margens de aceitabilidade de condições térmicas para o ambiente, de forma mais incisiva.

Em contrapartida, Morello (2005) sugere que o número de horas de desconforto térmico admissíveis para uma edificação, quando não for possível levantar-se o grau de aceitabilidade dos usuários, seja o correspondente ao número de horas de desconforto térmico, que não podem ser resolvidas por meio do condicionamento térmico passivo, ou seja, não podem ser resolvidas com o projeto arquitetônico, conforme as zonas fornecidas pela carta bioclimática de Givoni (1992). Esta seria uma forma mais direta de estipular a percentagem de horas de desconforto térmico admissíveis, enquanto não se dispõe de referências mais confiáveis.

Silva e Basso (2002) apresentam uma abordagem para avaliação de desempenho térmico de HIS usando os resultados encontrados por Barbosa (1997) e as normas desenvolvidas pela ABNT (2005). A partir das referências adotadas para simulação, os autores definiram uma pontuação para cada um dos requisitos considerados, que permite comparar diferentes soluções a partir do total de pontos alcançados. Esse método, embora não avance na avaliação global da mesma, é de fácil aplicação e entendimento, o que possibilita sua assimilação por agentes que atuam no setor.

Becker (1992) e Morello (2005) procederam a medições in loco para duas HIS desenvolvidas por centros de pesquisa (projetos 3 e 4 considerados neste estudo). Becker (1992) apresenta registros não corridos de medições in loco entre 22 de março e 2 de junho de 1990 para o projeto 3. Dezesseis dias não corridos de medições foram analisados. As variáveis medidas incluem temperatura do ar interno, temperatura do ar externo, temperatura superficial interna e temperatura de globo. A temperatura do ar interno e a temperatura de globo foram medidas em pontos a $1,5 \mathrm{~m}$ do piso e no centro geométrico dos cômodos analisados. Morello (2005) registrou medições in loco entre os dias 12 de maio de 2003 e 12 de maio de 2004, perfazendo um total de 8.784 horas de medições de temperatura do ar interno e umidade relativa do ar interno, com sensores localizados a $1,10 \mathrm{~m}$ de altura do piso.

Baseando-se nas referências acima apresentadas, entre outras, o objetivo deste estudo foi desenvolver um método de avaliação global de desempenho higrotérmico de habitações térreas unifamiliares de interesse social para condições climáticas específicas da cidade de Porto Alegre, no sul do Brasil. O método busca a avaliação 
global da edificação, através de requisitos e critérios que complementam aqueles propostos no conjunto de normas NBR 15220 (ABNT, 2005) e NBR 15575 (ABNT, 2008) e sejam aplicáveis às condições climáticas específicas daquela localidade.

\section{Método adotado}

O estudo partiu de pesquisa bibliográfica sobre o clima da região, variáveis climáticas e variáveis internas, para fins de análise do comportamento térmico, e parâmetros que expressassem o comportamento térmico global da edificação não incluídos nas normas brasileiras. O estudo também se fundamentou na análise de quatro habitações construídas em Porto Alegre (duas submetidas a medições in loco), consideradas por órgãos públicos e pesquisadores locais da área de conforto térmico como práticas aceitáveis para as condições econômicas e culturais do público-alvo (experiência na avaliação formal desse tipo de edificação e na constatação de seu bom ou mau desempenho durante seu uso por reclamações de usuários). Os projetos 3 e 4 foram desenvolvidos em centros de pesquisas locais e avaliados por Becker (1992) e Morello (2005). São edificações melhoradas em relação à prática corrente. As outras duas foram apontadas pelos órgãos públicos locais como solução viável e como solução considerada inadequada, a partir de sua experiência. Essa análise fez parte da definição de quais parâmetros térmicos seriam mais relevantes, bem como dos valores de referência para tais parâmetros.

A proposta foi submetida a agentes públicos envolvidos com o financiamento, projeto, execução, fiscalização e avaliação de HIS em Porto Alegre e a especialistas da área de conforto térmico que atuam em instituições brasileiras de pesquisa. Os agentes foram entrevistados pessoalmente (entrevista estruturada seguida de diálogo reflexivo), e os especialistas foram consultados via correio eletrônico, por meio de questionário de perguntas abertas e fechadas. Com as consultas, buscou-se verificar a relevância dos requisitos propostos e ajustar os valores de ponderação a eles atribuídos.

A partir daí, foram selecionados dezessete parâmetros térmicos, divididos em dois grupos (ligados a componentes e à edificação como um todo), com seus respectivos critérios de avaliação, indicados pesos para cada um deles, cujo total resultou em três classificações possíveis de serem atingidas por habitações térreas unifamiliares em Porto Alegre.

\section{Condições climáticas de Porto Alegre}

O Brasil situa-se aproximadamente entre o equador e o trópico de Capricórnio, apresentando seis tipos básicos de climas: equatorial, tropical, tropical de altitude, semiárido, tropical atlântico e subtropical. Porto Alegre, cidade ao sul do Brasil, com latitude, longitude e altitude iguais a $30^{\circ} 02^{\prime} \mathrm{S}, 51^{\circ} 11^{\prime}$ e 4 $\mathrm{m}$ respectivamente, situa-se na região com clima classificado como subtropical úmido. A cidade está em uma área do estado conhecida como Depressão Central, a qual se caracteriza por temperaturas médias superiores a $20,0^{\circ} \mathrm{C}$ em pelo menos 5 meses do ano, taxa de precipitação mensal de $90 \mathrm{~mm}$ a $190 \mathrm{~mm}$, com cerca de 100 a 126 dias chuvosos por ano, velocidade média do ar em torno de $2 \mathrm{~m} / \mathrm{s}$, com direção e sentido predominantes do quadrante leste. A região apresenta ondas de frio $\operatorname{raras}^{1}$ e ondas de calor frequentes (FORTES, 1959; MACHADO, 1950; SATTLER, 1987).

Devido à proximidade de uma grande massa de água, com o litoral a $100 \mathrm{~km}$ a leste e com uma serra a noroeste, o clima da área ocupada por Porto Alegre possui uma umidade relativa do ar alta, na maior parte do ano. Isso, associado à alta temperatura e à baixa velocidade do ar (situações que ocorrem frequentemente), contribui, durante verão, para uma sensação de desconforto térmico acentuada. Já no inverno a umidade alta do ar (média anual de 76\%) faz com que o problema de condensação em superfícies internas das edificações sejam reclamações frequentes de seus moradores. O clima da área também é caracterizado por amplitudes diárias de temperatura do ar externo superiores a $10{ }^{\circ} \mathrm{C}$ (SATTLER, 1987).

A Tabela 1 apresenta as normais climatológicas para Porto Alegre no período compreendido entre 1961 e 1990 (BRASIL, 2006).

Para Porto Alegre é importante considerar a possibilidade de condensação sobre superfícies internas, bem como a inércia térmica da edificação, como forma de amenização de grandes variações de temperatura externa. A NBR 15220 (ABNT, 2005c) faz referência à inércia térmica sem considerar os fechamentos externos (paredes internas pesadas) e expressa esse parâmetro de forma qualitativa. Seria desejável especificar o grau da inércia térmica para a edificação por meio de um parâmetro quantitativo.

\footnotetext{
${ }^{1}$ Segundo Machado (1950), ondas de frio, ou seja, períodos em que as temperaturas máximas diárias caem cerca de 10 ${ }^{\circ} \mathrm{C}$ em $24 \mathrm{~h}$, duram de 3 a 4 dias. Na região de Porto
}

Alegre, ocorre em torno de uma onda de frio por ano. 


\begin{tabular}{|c|c|c|c|c|c|c|c|c|}
\hline \multirow[b]{2}{*}{ Mês } & \multicolumn{5}{|c|}{ Temperatura do ar $\left({ }^{\circ} \mathrm{C}\right)$} & \multirow[b]{2}{*}{$\begin{array}{l}5 \\
b\end{array}$} & \multirow{2}{*}{ 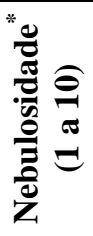 } & \multirow[b]{2}{*}{ 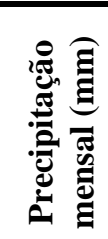 } \\
\hline & 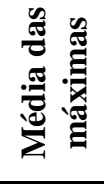 & 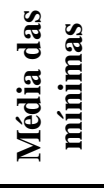 & 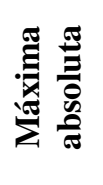 & 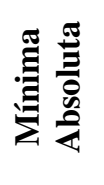 & 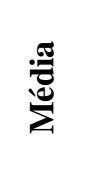 & & & \\
\hline Jan & 30,2 & 20,5 & 39,1 & 11,4 & 24,6 & 71,0 & 5,3 & 100,1 \\
\hline $\mathrm{Fev}$ & 30,1 & 20,8 & 37,9 & 12,6 & 24,7 & 74,0 & 5,1 & 108,6 \\
\hline Mar & 28,3 & 19,3 & 38,1 & 9,6 & 23,1 & 75,0 & 5,5 & 104,4 \\
\hline Abr & 25,2 & 16,3 & 34,6 & 6,8 & 20,1 & 77,0 & 5,1 & 86,1 \\
\hline Mai & 22,1 & 13,0 & 32,6 & 3,3 & 16,8 & 81,0 & 5,5 & 94,6 \\
\hline Jun & 19,4 & 10,7 & 31,5 & 0,7 & 14,3 & 82,0 & 5,8 & 132,7 \\
\hline Jul & 19,7 & 10,7 & 32,9 & 1,2 & 14,5 & 81,0 & 5,7 & 121,7 \\
\hline Ago & 20,4 & 11,5 & 34,9 & 1,1 & 15,3 & 79,0 & 5,8 & 140,0 \\
\hline Set & 21,8 & 13,1 & 35,8 & 2,2 & 16,8 & 78,0 & 6,0 & 139,5 \\
\hline Out & 24,4 & 15,0 & 36,5 & 6,2 & 19,3 & 74,0 & 5,6 & 114,3 \\
\hline Nov & 26,7 & 17,0 & 39,8 & 8,7 & 21,3 & 71,0 & 5,4 & 104,2 \\
\hline Dez & 29,0 & 18,9 & 39,2 & 11,4 & 23,2 & 69,0 & 5,0 & 101,2 \\
\hline A & & & 39,8 & 0,7 & & & & \\
\hline Média & 24,8 & 15,6 & & & 19,5 & 76,0 & 5,5 & $1.347,4$ \\
\hline
\end{tabular}

* Quantidade relativa de nuvens visíveis no céu, 0 equivalendo a céu totalmente descoberto e 10 a céu totalmente encoberto

Tabela 1 - Normais Climatológicas no período de 1961 a 1990 para Porto Alegre

\begin{tabular}{l|c}
\hline Exigências de inverno & \\
\hline $\begin{array}{l}\text { Temperatura do ar externo, de cálculo } \\
\text { Amplitude típica da onda de temperatura do ar } \\
\text { externo, dos dias considerados frios }\end{array}$ & $\mathrm{t}_{\mathrm{e}}=7,5^{\circ} \mathrm{C}$ \\
\hline $\begin{array}{l}\text { Umidade relativa média do ar, dos dias } \\
\text { considerados frios }\end{array}$ & $10,0 \mathrm{~K}$ \\
\hline $\begin{array}{l}\text { Temperatura do ar interno, de cálculo } \\
\text { Exigências de verão }\end{array}$ & $\mathrm{UR}=95,0 \%$ \\
\hline $\begin{array}{l}\text { Temperatura máxima do ar externo, de base } \\
\text { Temperatura mínima do ar externo, de base }\end{array}$ & $33,0^{\circ} \mathrm{C}$ \\
\hline $\begin{array}{l}\text { Umidade relativa do ar, concomitante à } \\
\text { temperatura do ar externo, de base, máxima }\end{array}$ & $23,0{ }^{\circ} \mathrm{C}$ \\
\hline Temperatura do ar interno, de cálculo & $\mathrm{UR}=72,0 \%$ \\
\hline
\end{tabular}

Tabela 2 - Exigências higrotérmicas adotadas para inverno e verão

\section{Variáveis climáticas, variáveis internas e condições de conforto}

As variáveis climáticas e as variáveis internas constituem-se em temperaturas médias do ar externo e suas variações, umidade relativa do ar e intensidade de radiação solar global por orientação solar (AROZTEGUI; BRIZOLARA, 1980) e são apresentadas na Tabela 2. As temperaturas do ar interno de cálculo, para a situação de inverno e de verão, são iguais aos limites inferior e superior da zona de conforto estabelecidos por Givoni (1992).

Para a situação de inverno, considera-se o dia típico de projeto com nível 10\%, conforme Goulart (1997). Para a situação de verão, considera-se, para temperatura do ar externo, $\mathrm{t}_{\mathrm{e}}$, a temperatura ar-sol, $\mathrm{T}_{\mathrm{ar}-\mathrm{sol}}$, conforme Aroztegui (1980).
As condições de conforto térmico (GIVONI, 1992) são definidas por temperatura mínima do ar interno, para a situação de inverno, igual a $18,0^{\circ} \mathrm{C}$, temperatura máxima do ar interno, para a situação de verão, igual a $29,0^{\circ} \mathrm{C}$, e umidade relativa do ar, no inverno e no verão, nunca maior que $80,0 \%$.

\section{Parâmetros térmicos globais}

Além dos parâmetros térmicos resistência térmica total, $\mathrm{R}_{\mathrm{T}}$; transmitância térmica, $\mathrm{U}$; atraso térmico, $\varphi$, e fator de calor solar, FCS, relativos a paredes e cobertura definidos pela ABNT (2005a, 2005b), são propostos parâmetros térmicos globais, que se seguem. 


\section{Coeficiente de amortecimento}

$O$ coeficiente de amortecimento, $\mu$, é a relação entre a amplitude máxima atingida pela temperatura superficial interna de um fechamento externo e a amplitude máxima da temperatura do ar externo (GIVONI, 1981) e é dado pela eq. 1:

$\mu=e^{-0,1309 \times R_{t} \times \sqrt{B_{1}+B_{2}}}$

Eq. 1

Os coeficientes B1 e B2 são definidos pela ABNT (2005b).

\section{Coeficientes volumétricos globais de perda e ganho de calor}

O coeficiente volumétrico global de perda de calor, GVinverno, expresso em $\mathrm{W} / \mathrm{m}^{3} . K$, é definido como a razão entre a taxa de fluxo total de calor, Q, que atravessa todos os fechamentos da edificação e o volume total delimitado por sua envolvente, pela diferença de temperatura entre o ar interno e o externo (GIVONI, 1981).

$$
G V_{\text {inverno }}=\frac{Q_{T}}{V \times\left(t_{e}-t_{i}\right)}
$$

Pode-se decompor GVinverno em cada uma das contribuições diferentes que promovem a transferência de calor do interior para o exterior da edificação, na situação de inverno: renovação do ar interior através de infiltrações; e perdas térmicas através de fechamentos opacos e transparentes.

O coeficiente volumétrico global de ganho de calor, GVverão, é definido de forma similar ao GVinverno, considerando o fluxo máximo de calor, Qmáx, que é encontrado a partir do horário correspondente à maior temperatura ar-sol, Tarsol, de acordo com a orientação solar, para cada componente da envolvente da edificação.

\section{Possibilidade de condensação sobre paredes e coberturas}

Para a análise da possibilidade de haver condensação sobre as superfícies internas da edificação, paredes e forro, situação de inverno, à noite, em regime permanente, para condições de temperatura do ar interno, temperatura do ar externo e umidade relativa do ar predefinidas, considera-se a temperatura superficial interna, tsi, correspondente a esses elementos (ISO, 2001).

\section{Assimetria da radiação térmica}

$O$ efeito de superfícies frias sobre a homogeneidade do conforto (diferenças de temperaturas superficiais internas, tsi, responsáveis pelas trocas térmicas por radiação) pode ser analisado a partir do conceito de temperatura radiante plana. A temperatura radiante plana, Trp, é a temperatura superficial interna uniforme de um ambiente no qual o fluxo de radiação incidente em um lado de um plano infinitesimal é o mesmo que no ambiente real, não uniforme, e é um indicativo adequado da diferença de temperatura superficial interna, tsi, em sentidos opostos, sendo expressa em graus Celsius (ABNT, 2005a). A temperatura radiante plana é função das temperaturas superficiais internas, tsi, e dos fatores de forma correspondentes a cada superfície i (ISO, 1996):

$T_{r p}=\sum_{i} t_{s i} \times f_{i}$

Eq. 3

Os fatores de forma, fi, são obtidos para cada superfície i, que é vista do ponto e da direção em que se encontra o plano infinitesimal imaginário. Os fatores de forma, fi, são calculados segundo normas definidas em ISO (1996).

Para fins de análise, indica-se tomar, para condições de inverno, os ambientes que possuam menores temperaturas superficiais internas para seus fechamentos, ambientes com grandes superfícies transparentes sem proteção opaca e que são de permanência noturna. Para condições de verão, a seleção dos ambientes deve satisfazer à condição de possuírem paredes externas voltadas a oeste, noroeste ou sudoeste, pois esses fechamentos apresentam maiores temperaturas superficiais durante o dia, na situação de calor. Além dos ambientes citados, a análise do efeito do forro deve ser efetuada.

$\mathrm{O}$ valor da assimetria da radiação térmica, $\Delta \operatorname{Trp}$, segundo recomendações da ASHRAE (2005), deve ser, no máximo, igual a $9{ }^{\circ} \mathrm{C}$ para forros ou coberturas quentes e a $14{ }^{\circ} \mathrm{C}$ para paredes, considerando $20,0 \%$ de pessoas insatisfeitas.

\section{Coeficiente de superfície pesada equivalente coef $f_{S P E}$}

Aroztegui e Brizolara (1980) indicam o uso do conceito de superfície pesada equivalente, SPE, para caracterizar o efeito de inércia térmica da edificação, como um todo, consequência da acumulação de calor nos fechamentos (paredes externas e piso) e partições internas de uma edificação. A superfície pesada equivalente, SPE, é definida como a soma das áreas de todas as partições internas e fechamentos externos, abrigados da radiação solar direta (para Porto Alegre, fechamentos voltados a sudeste e sulsudoeste e fechamentos com camada de isolamento térmico voltada ao exterior), multiplicados por um coeficiente que depende da relação entre a massa e a área do fechamento e da resistência térmica de sua camada mais interna (no caso de paredes externas e piso). 
Para encontrar a categoria de inércia térmica da edificação, determina-se o coeficiente de inércia dos fechamentos a partir da resistência térmica média dos revestimentos internos destes, de partições internas e da razão entre a massa e a área dos mesmos. O coeficiente de superfície pesada equivalente, coefSPE, será dado através da análise desses valores. A partir do valor do coeficiente de superfície pesada equivalente, coefSPE, pode-se classificar a inércia térmica da edificação em muito fraca, fraca, média e forte (FROTA; SCHIFFER, 1995), conforme o Quadro 1.

\section{Efusividade térmica de ambientes}

Para um ambiente, a efusividade térmica, ef, pode ser calculada a partir da média ponderada da efusividade térmica, efi, de cada superfície que delimita o ambiente (paredes, piso e forro), em relação às áreas, $\mathrm{Si}$, de cada uma delas (vide equação 4) (GOULART, 2004). Ou seja, ela é característica dos revestimentos dos fechamentos que delimitam o ambiente.

$$
e f_{\text {amb }}=\frac{\sum_{i}\left(S_{i} \times e f_{i}\right)}{\sum_{i} S_{i}}
$$

Essa propriedade permite a análise de ambientes onde há ganhos de calor, tais como radiação solar penetrando por uma janela, ventilação natural ou fontes internas de calor (GIVONI, 1981).

Além dos parâmetros térmicos apresentados acima, foram considerados índices que representam características geométricas dos projetos. A taxa da área da cobertura voltada a sul ou sudeste pela área total da cobertura, coefcoberturaS, indica a orientação solar preferencial da cobertura, para a situação de verão, objetivando reduzir os ganhos térmicos por esse fechamento. A taxa da área da parede voltada a norte ou nordeste pela área da envolvente vertical, coefparedeN, indica a importância da parede voltada para norte ou nordeste nas trocas térmicas entre a edificação e o meio que a circunda. Também são consideradas características qualitativas da edificação: a orientação solar da edificação, a orientação solar das aberturas dos cômodos de maior permanência, os dispositivos opacos de aberturas de dormitórios, a proteção contra a radiação solar de aberturas, a ventilação da cobertura com forro, o sombreamento da parede oeste, a ventilação cruzada, a captação de ventos de verão, a ventilação noturna, a orientação da cobertura e a sua maior água voltada para sul.

\section{Habitações analisadas}

O Quadro 2 apresenta os quatro projetos selecionados para análise. Os projetos 3 e 4 são considerados práticas melhoradas em relação ao projeto padrão adotado por órgãos públicos municipais e estaduais no Rio Grande do Sul (projetos 1 e 2).

\section{Consulta a agentes e especialistas}

A consulta a especialistas buscou levantar sua prática na avaliação do desempenho térmico de edificações, bem como suas necessidades ante sua rotina de trabalho. Os agentes foram escolhidos com base em sua atuação profissional. Foram consultados sete agentes atuando em órgãos e empresas públicas, envolvidos em financiamento, projeto, construção, fiscalização e avaliação de HIS em Porto Alegre. Devido ao caráter das informações e discussões buscadas junto aos agentes (levantamento de problemas referentes a HIS verificados pelos entrevistados em sua prática profissional, apresentação do método e discussão pautada no conhecimento dos entrevistados), optou-se pela entrevista semiestruturada, com diálogo reflexivo, de tal forma que houvesse flexibilidade para permitir que eles expressassem, com maior liberdade, sua opinião sobre o assunto.

Adicionalmente, vinte e dois especialistas da área de conforto térmico de edificações atuando em instituições brasileiras de ensino e pesquisa foram solicitados a expressar sua opinião a respeito do método proposto e a relevância dos parâmetros, através de ponderação por eles conferida, procedimentos de cálculo e problemas verificados em sua prática profissional. $\mathrm{O}$ instrumento utilizado foi questionário de perguntas abertas e fechadas enviado via correio eletrônico. Entre os contatados, seis responderam ao questionário.

\begin{tabular}{|l|c|}
\hline \multicolumn{1}{|c|}{ Coeficiente de superfície pesada equivalente coef } \\
spe & Categoria de inércia \\
\hline $\operatorname{coef}_{\mathrm{SPE}}<0,5$ & Muito fraca \\
\hline $0,5 \leq \operatorname{coef}_{\mathrm{SPE}} \leq 1,5$ & Fraca \\
\hline $\operatorname{coef}_{\mathrm{SPE}}>1,5$, para massa/área da metade das paredes $<300 \mathrm{~kg} / \mathrm{m}^{2}$ & Média \\
\hline $\operatorname{coef}_{\mathrm{SPE}}>1,5$, para massa/área da metade das paredes $>300 \mathrm{~kg} / \mathrm{m}^{2}$ & Forte \\
\hline
\end{tabular}

Quadro 1 - Categoria de inércia térmica de uma edificação, a partir do coeficiente de superfície pesada equivalente coef $_{\mathrm{SPE}}$ 


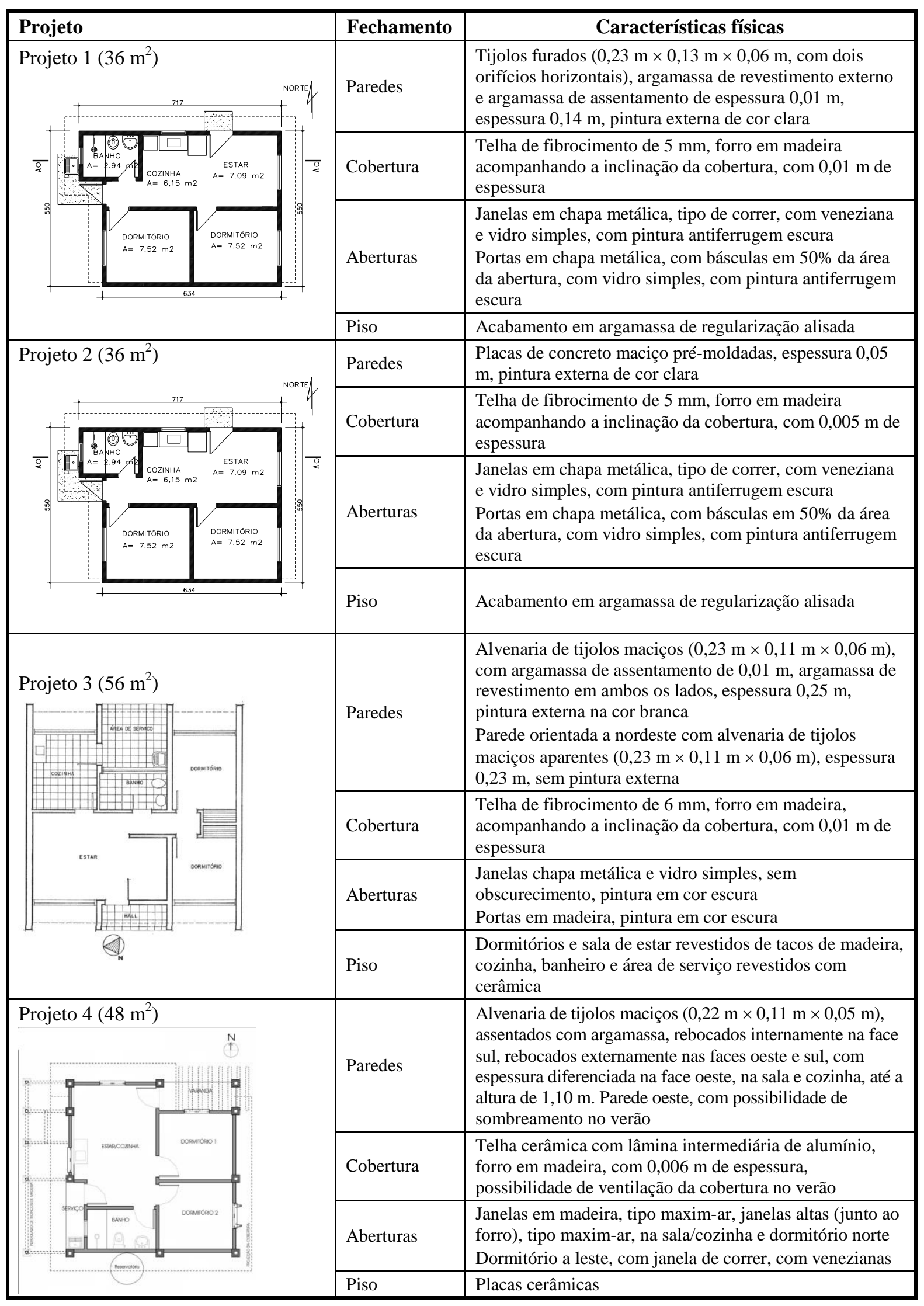

Quadro 2 - Características físicas dos projetos submetidos à análise com o método proposto (continuação) 


\section{Resultados}

\section{Parâmetros térmicos propostos}

O conjunto inicial de parâmetros térmicos, selecionado da literatura e exposto à apreciação dos agentes e especialistas, é indicado no Quadro 3.

\section{Análise das habitações selecionadas}

A Tabela 3 apresenta os resultados obtidos para os parâmetros térmicos dos fechamentos (paredes e coberturas) para as quatro habitações selecionadas.
$\mathrm{O}$ projeto 1 não satisfaz aos valores máximos recomendados pela ABNT (2005c) para a transmitância térmica (valor máximo de $2,0 . \mathrm{W} / \mathrm{m}^{2} . K$ ) de coberturas. O projeto 2 não satisfaz aos critérios para transmitância térmica e FCS para paredes (valor máximo de $3,6 . W / \mathrm{m}^{2} . K$ e $4,0 \%$ ) e transmitância térmica para coberturas. Para 0 projeto 3, o parâmetro térmico atraso térmico máximo de paredes não satisfaz ao valor recomendado, cujo limite é 4,3 h, e a cobertura não satisfaz ao valor recomendado para transmitância térmica. Para o projeto 4, o parâmetro térmico FCS não é satisfeito.

\begin{tabular}{|l|l|}
\hline Parâmetro térmico & \multicolumn{1}{|c|}{ Influência no comportamento térmico da edificação } \\
\hline Fechamentos & \multicolumn{1}{|c|}{} \\
\hline $\mathrm{R}_{\mathrm{T}}$ e $\mathrm{U}$ & $\begin{array}{l}\text { Densidade de fluxo de calor q, para situação de inverno, temperatura } \\
\text { superficial interna, } \mathrm{t}_{\mathrm{si}}\end{array}$ \\
\hline$\varphi$ & $\begin{array}{l}\text { Defasagem entre as temperaturas máximas ocorridas no exterior e interior, } \\
\text { com radiação solar direta (verão) }\end{array}$ \\
\hline$\mu$ & Redução de amplitude de onda de temperatura do ar interno \\
\hline $\mathrm{FCS}$ & Incremento de ganhos de calor devido à radiação solar \\
\hline$\propto$ & Absorção ou reflexão da radiação solar \\
\hline Edificação & \\
\hline $\mathrm{GV}_{\text {inverno e }} \mathrm{GV}_{\text {verão }}$ & Fluxo de calor entre interior e exterior, para situação de inverno e verão \\
\hline $\mathrm{t}_{\mathrm{si}}$ & Condensação sobre superfícies internas \\
\hline$\Delta \mathrm{T}_{\mathrm{rp}}$ & Diferença entre as $\mathrm{t}_{\mathrm{si}}$ e trocas térmicas por radiação \\
\hline coef & Armazenagem de calor nos fechamentos e partições internas da edificação \\
\hline ef $\mathrm{f}_{\mathrm{SPb}}$ & Capacidade da edificação em armazenar calor \\
\hline coef & Comportamento global da edificação diante da passagem de fluxo de calor, $\mathrm{Q}$ \\
\hline
\end{tabular}

Quadro 3 - Resumo dos parâmetros térmicos propostos

\begin{tabular}{|c|c|c|c|c|c|}
\hline Fechamento & Parâmetro & Projeto 1 & Projeto 2 & Projeto 3 & Projeto 4 \\
\hline \multirow{6}{*}{ Parede } & $\mathrm{R}_{\mathrm{T}}\left(\frac{m^{2} K}{W}\right)$ & 0,3433 & 0,1984 & 0,5430 & 0,2857 \\
\hline & $\mathrm{U}\left(\frac{W}{m^{2} K}\right)$ & 2,91 & 5,04 & 1,84 & 3,50 \\
\hline & $\varphi(\mathrm{h})$ & 3,39 & 1,30 & 7,78 & 2,76 \\
\hline & $\mu$ & 0,7250 & 0,8841 & 0,4786 & 0,7702 \\
\hline & $\alpha$ & 0,30 & 0,30 & 0,30 & 0,80 \\
\hline & FCS (\%) & 3,49 & 6,05 & 2,21 & 11,20 \\
\hline \multirow{6}{*}{$\begin{array}{l}\text { Cobertura } \\
\text { (inverno/ } \\
\text { Verão) }\end{array}$} & $\mathrm{R}_{\mathrm{T}}\left(\frac{m^{2} K}{W}\right)$ & $0,3567 / 0,4967$ & $0,1810 / 0,2510$ & $0,3216 / 0,4616$ & $0,6100 / 1,0600$ \\
\hline & $\mathrm{U}\left(\frac{W}{m^{2} K}\right)$ & $2,80 / 2,01$ & $3,12 / 2,17$ & $3,11 / 2,17$ & $1,64 / 0,94$ \\
\hline & $\varphi(\mathrm{h})$ & $1,14 / 1,31$ & $0,73 / 0,86$ & $0,55 / 0,65$ & $1,21 / 1,62$ \\
\hline & $\mu$ & $\begin{array}{l}0,90 \\
0,88 \\
\end{array}$ & $\begin{array}{l}0,93 \\
0,92 \\
\end{array}$ & $\begin{array}{l}0,95 \\
0,94 \\
\end{array}$ & $\begin{array}{l}0,89 \\
0,86 \\
\end{array}$ \\
\hline & $\alpha$ & $0,50 / 0,50$ & $0,50 / 0,50$ & $0,50 / 0,50$ & $0,80 / 0,80$ \\
\hline & FCS (\%) & $5,60 / 4,02$ & $6,24 / 4,34$ & $6,22 / 4,33$ & $5,25 / 3,01$ \\
\hline
\end{tabular}

Tabela 3 - Parâmetros térmicos dos fechamentos das quatro habitações selecionadas 


\begin{tabular}{|c|c|c|c|c|}
\hline Parâmetros térmicos & 1 & 2 & 3 & 4 \\
\hline $\mathrm{GV}_{\text {inverno }}$ & $3,78 \frac{W}{m^{3 \circ} C}$ & $5,29 \frac{W}{m^{3 \circ} C}$ & $3,32 \frac{W}{m^{3}{ }^{\circ} C}$ & $2,89 \frac{W}{m^{3 \circ} C}$ \\
\hline $\mathrm{t}_{\mathrm{si}} \times \mathrm{t}_{\text {orvalho }}$ & Sim & Sim & Sim & Sim \\
\hline$\Delta \mathrm{T}_{\mathrm{rp}}$ & $\begin{array}{l}\text { Cobertura não } \\
\text { satisfaz }\end{array}$ & $\begin{array}{l}\text { Cobertura não } \\
\text { satisfaz }\end{array}$ & $\begin{array}{l}\text { Cobertura não } \\
\text { satisfaz }\end{array}$ & $\begin{array}{l}\text { Cobertura não } \\
\text { satisfaz }\end{array}$ \\
\hline $\mathrm{GV}_{\text {verão }}$ & $17,13 \frac{W}{m^{3}{ }^{\circ} C}$ & $18,76 \frac{W}{m^{3 \circ} \mathrm{C}}$ & $22,69 \frac{W}{m^{3 \circ} \mathrm{C}}$ & $19,47 \frac{W}{m^{30} \mathrm{C}}$ \\
\hline $\operatorname{coef}_{\mathrm{SPE}}$ & 1,97 (média) & 1,00 (fraca) & 1,62 (média) & 1,85 (média) \\
\hline $\mathrm{ef}_{\mathrm{amb}}$ & $1.234,61 \frac{W \times s^{\frac{1}{2}}}{m^{2 \circ} C}$ & $2.039,53 \frac{W \times s^{\frac{1}{2}}}{m^{2 \circ} C}$ & $977,49 \frac{W \times s^{\frac{1}{2}}}{m^{2 \circ} C}$ & $1.117,40 \frac{W \times s^{\frac{1}{2}}}{m^{2 \circ} C}$ \\
\hline $\operatorname{coef}_{\text {coberturas }}$ & $\begin{array}{l}\text { Sem orientação } \\
\text { sugerida }\end{array}$ & $\begin{array}{l}\text { Sem orientação } \\
\text { sugerida }\end{array}$ & 0,54 & 0,88 \\
\hline coef $_{\text {paredeN }}$ & 0,30 & 0,30 & 0,23 & 0,37 \\
\hline
\end{tabular}

Tabela 4 - Parâmetros térmicos globais para as quatro habitações

A Tabela 4 apresenta o resultado para os parâmetros térmicos globais.

Os projetos 3 e 4 apresentam melhor desempenho do que o projeto 1 , considerado como prática local para HIS. O projeto 1 apresenta problemas de assimetria da radiação térmica para a cobertura, para a situação de verão, o mesmo ocorrendo para o 3 e o 4. A despeito desse desempenho desfavorável, assumem-se os valores dos parâmetros térmicos atingidos pelos projetos, como valores de referência propostos no método, uma vez que a satisfação desse critério implicaria custos adicionais na solução da cobertura.

Os projetos 3 e 4 haviam sido, em pesquisas anteriores, submetidos a medições in loco (BECKER, 1992; MORELLO, 2005).

Da análise dos dados, conclui-se que:

(a) a frequência de dias com amplitudes superiores a $10^{\circ} \mathrm{C}$ sugere exploração da inércia térmica da edificação;

(b) na situação de verão, temperaturas abaixo dos $29^{\circ} \mathrm{C}$, a partir das $19 \mathrm{~h} 00$, com defasagem aproximada de $4 \mathrm{~h}$, em relação à maior temperatura registrada durante o dia, sugere um atraso térmico mínimo de 4 h;

(c) valores de atraso térmico mínimos para garantir inércia térmica ante a grandes amplitudes diárias de temperatura;

(d) medições in loco devem abranger, no mínimo, um período de sete dias consecutivos; e

(e) as edificações são mais exigidas na situação de inverno do que na situação de verão.

O Quadro 4 apresenta os resultados e conclusões gerais, obtidos da análise do comportamento térmico medido in loco para os projetos 3 e 4 .
De modo geral, os projetos 3 e 4 apresentaram bom desempenho, justificando sua escolha como padrões melhorados para HIS.

\section{Consulta a agentes e especialistas}

O Quadro 5 traz problemas, práticas e sugestões apresentados pelos agentes e especialistas da área de conforto térmico.

Os especialistas concederam valores de 0 (não tem conhecimento sobre o assunto) a 5 (fundamental sua consideração) para os requisitos propostos no método. O Quadro 6 apresenta os requisitos segundo a ordem de relevância indicada pelos especialistas, a partir da média dos pesos por eles conferidos.

Orientação solar, dispositivos de sombreamento em aberturas, orientação solar dos cômodos para inverno foram os considerados mais importantes pelos especialistas. A inércia térmica também é apontada como um requisito importante a ser satisfeito pela edificação. A ventilação natural, estratégia importante para a situação de verão, aparece representada pelos requisitos ventilação cruzada, captação de ventos no verão, ventilação da cobertura e ventilação noturna.

\section{Proposta final do método}

A partir da análise dos resultados, a efusividade térmica média e a assimetria da radiação térmica foram retiradas por não reproduzirem diferenças entre os projetos analisados. A orientação solar preferencial para cômodos foi retirada, uma vez que as medições não indicaram diferenças significativas entre suas temperaturas. A orientação da cobertura e a proporção de águas norte e sul não foram consideradas relevantes 
pelos especialistas. $\mathrm{O}$ coeficiente de amortecimento pode ser representado pelo atraso térmico. A transmitância térmica e a absortância da cobertura, para o verão, e das paredes estão incluídas no FCS. A ventilação da cobertura não foi considerada relevante pelos especialistas.

Os requisitos propostos foram divididos em quatro grupos (edificação, cobertura, paredes e fechamentos transparentes), apresentados na Tabela 5. Entre os parâmetros térmicos incluem-se aqueles propostos pelas normas brasileiras. Os valores de atraso térmico propostos pelas normas são limitados a um valor máximo. Neste estudo adota-se um valor mínimo, uma vez que se considera desejável a inércia térmica dos fechamentos externos.

\begin{tabular}{|c|l|}
\hline Projeto & \multicolumn{1}{c|}{ Resultados } \\
\hline \multirow{4}{*}{3} & $\begin{array}{l}\text { Não há diferença significativa entre as temperaturas do ar interno medidas para os } \\
\text { diferentes cômodos, para o período de medições }\end{array}$ \\
\cline { 2 - 3 } & Coeficiente de amortecimento médio atingido: entre 0,4 a 0,5 \\
\cline { 2 - 3 } & Cobertura apresenta maior valor para temperatura superficial interna \\
\cline { 2 - 3 } & Pequena diferença verificada entre temperaturas de globo e temperaturas do ar interno \\
\hline \multirow{4}{*}{4} & Resposta rápida às quedas de temperatura (frentes frias) \\
\cline { 2 - 3 } & Temperatura de globo inferior ao limite inferior da zona de conforto de Givoni \\
\cline { 2 - 3 } & $\begin{array}{l}\text { Para condições de frio, temperatura do ar interno mantém-se próxima das temperaturas } \\
\text { máximas do ar externo }\end{array}$ \\
\cline { 2 - 3 } & $\begin{array}{l}\text { Para condições de calor, temperatura do ar interno mantém-se abaixo do limite superior } \\
\text { da zona de conforto de Givoni }\end{array}$ \\
\hline
\end{tabular}

Quadro 4 - Resultados da análise de medições in loco para os projetos 3 e 4

\begin{tabular}{|c|c|c|c|}
\hline \multirow{2}{*}{ Fonte } & \multicolumn{3}{|c|}{ Resultados } \\
\hline & Problemas & Práticas & Sugestões \\
\hline \multirow{3}{*}{ 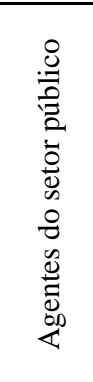 } & $\begin{array}{l}\text { Poucas contribuições para crítica } \\
\text { dos parâmetros }\end{array}$ & $\begin{array}{l}\text { Uso da arborização do } \\
\text { espaço público como } \\
\text { coadjuvante do controle } \\
\text { do microclima; } \\
\text { orientação da edificação } \\
\text { em relação ao norte }\end{array}$ & Desenvolvimento de um manual do usuário \\
\hline & $\begin{array}{l}\text { Falta de avaliação pós-ocupação para } \\
\text { retroalimentação das equipes de } \\
\text { projeto }\end{array}$ & $\begin{array}{l}\text { Prescrições qualitativas } \\
\text { ou verificação expedita } \\
\text { de conformidade }\end{array}$ & $\begin{array}{l}\text { Soluções diferenciadas conforme faixa de } \\
\text { renda }\end{array}$ \\
\hline & $\begin{array}{l}\text { Entrega de habitações incompletas } \\
\text { para usuário final }\end{array}$ & & \\
\hline \multirow{6}{*}{ 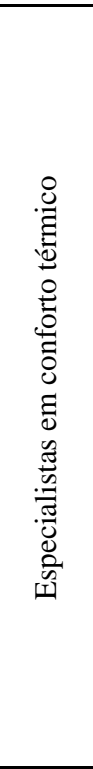 } & $\begin{array}{l}\text { Temperatura do ar interno baixa no } \\
\text { inverno (associada a camadas e } \\
\text { espessuras de paredes e coberturas) }\end{array}$ & $\begin{array}{l}\text { Seguem recomendações } \\
\text { constantes na NBR } \\
15220 \text { para avaliação }\end{array}$ & $\begin{array}{l}\text { Adoção de métodos padronizados para } \\
\text { avaliação das habitações, seja através de } \\
\text { medições in loco, seja por simulações } \\
\text { computacionais }\end{array}$ \\
\hline & $\begin{array}{l}\text { Problemas de temperatura do ar } \\
\text { interno alta no verão (associada à } \\
\text { ausência de dispositivos que } \\
\text { permitam ventilação noturna, } \\
\text { camadas e espessuras de paredes e } \\
\text { coberturas, tamanho de aberturas } \\
\text { para ventilação) }\end{array}$ & & $\begin{array}{l}\text { Temperatura mínima do ar interno para } \\
\text { situação de inverno para fins de simulação } \\
\text { deve estar entre } 16^{\circ} \mathrm{Ce} 18^{\circ} \mathrm{C}\end{array}$ \\
\hline & & & $\begin{array}{l}\text { Adequação dos parâmetros atraso térmico e } \\
\text { coeficiente de superfície pesada para } \\
\text { verificação da inércia térmica }\end{array}$ \\
\hline & & & $\begin{array}{l}\text { Uso de percentuais de área de aberturas em } \\
\text { relação a áreas de piso é insuficiente para } \\
\text { indicar condições de ventilação natural }\end{array}$ \\
\hline & & & $\begin{array}{l}\text { Análise da assimetria da radiação térmica não } \\
\text { é aplicável a HIS }\end{array}$ \\
\hline & & & $\begin{array}{l}\text { Flexibilidade para a orientação solar } \\
\text { preferencial para adequação às condições do } \\
\text { entorno imediato }\end{array}$ \\
\hline
\end{tabular}

Quadro 5 - Problemas, práticas e sugestões de agentes e especialistas 
Pontuação 3,6 a 4,8

Inércia térmica; orientação solar; orientação solar das aberturas dos cômodos de maior permanência; dispositivos opacos de aberturas de dormitórios; proteção contra a radiação solar de aberturas

\section{Pontuação 2,4 a 3,5}

Coeficiente volumétrico global de perdas e ganhos de calor; ventilação da cobertura com forro (verão); sombreamento da parede oeste (verão); ventilação cruzada; captação de ventos de verão; ventilação noturna

Pontuação 1,2 a 2,3

Efeito de superfícies frias e quentes sobre homogeneidade do conforto; orientação da cobertura; maior água voltada a sul

Quadro 6 - Classificação dos requisitos propostos por ordem de relevância

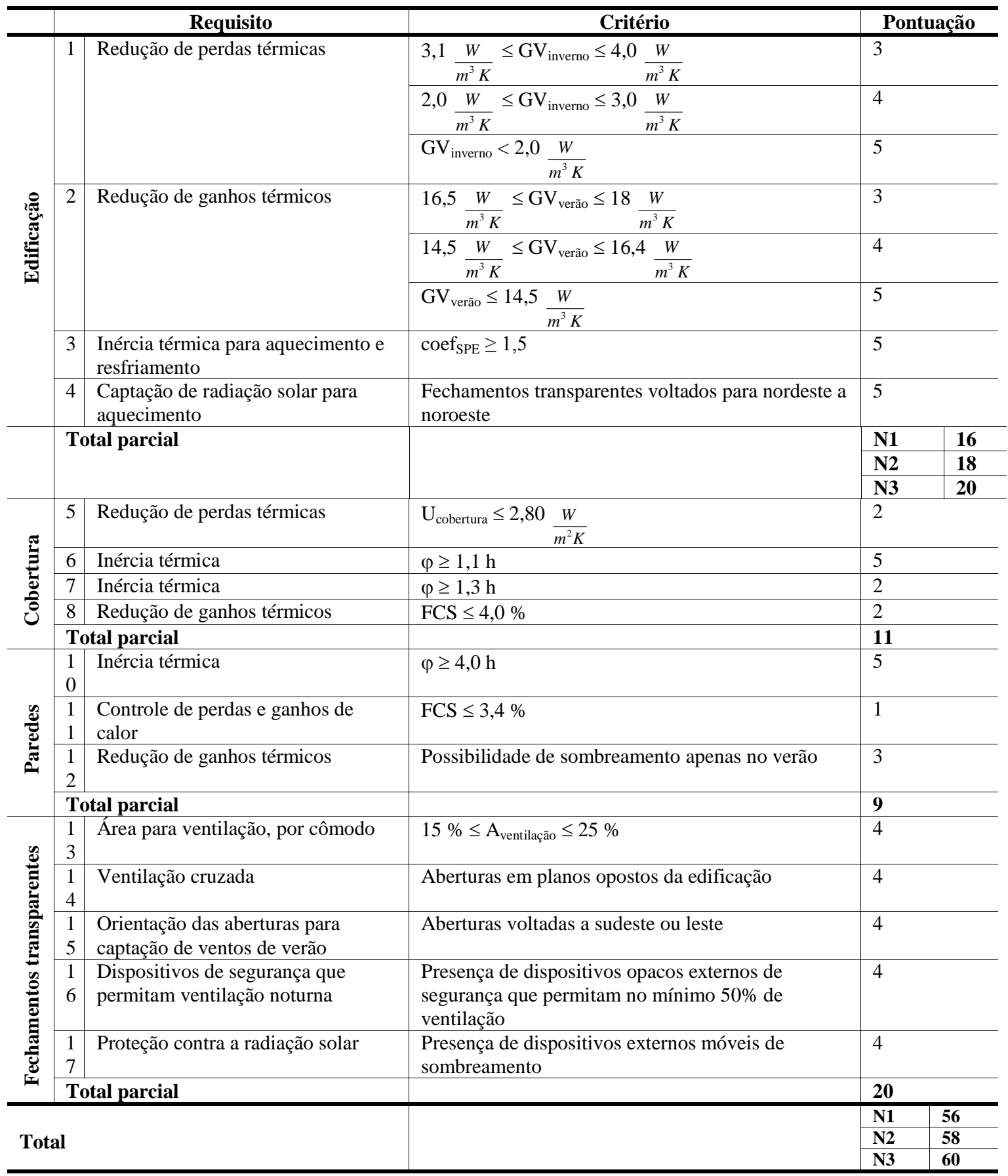

Tabela 5 - Parâmetros térmicos e diretrizes finais 


\begin{tabular}{|c|c|c|}
\hline Classificação & Avaliação & Pontuação \\
\hline A & Ótimo & 51 a 60 \\
\hline B & Médio & 46 a 50 \\
\hline C & Mínimo aceitável & 40 a 45 \\
\hline
\end{tabular}

Quadro 7- Classificações possíveis para HIS segundo o método proposto

Os quatro projetos analisados geraram três classificações possíveis, conforme o Quadro 7.

O máximo de pontos a ser atingido por determinado projeto, segundo os critérios adotados no método proposto, é 60 (sessenta pontos). O projeto 1 , projeto considerado como prática aceitável pelos agentes, atingiu uma pontuação de 41 pontos, próximo às pontuações atingidas pelos projetos 3 (50 pontos) e 4 (48 pontos), com transmitância térmica, FCS, atraso térmico e coeficiente de amortecimento mais favoráveis do que o primeiro, o que era o resultado esperado. $\mathrm{O}$ projeto 2, considerado como solução desfavorável, atinge a menor pontuação (23 pontos), com desempenho cerca de $50 \%$ abaixo daquele atingido pelos demais projetos.

\section{Conclusões}

Com base nos resultados deste estudo podem ser apontadas as seguintes conclusões e recomendações gerais:

(a) para edificações de até $60 \mathrm{~m}^{2}$, a orientação dos cômodos não tem influência significativa na temperatura do ar interno;

(b) buscar obter o valor de referência de aproximadamente 0,5 para o coeficiente de amortecimento da edificação;

(c) corroboração da importância da cobertura para habitações térreas leva ao estabelecimento de valor-limite máximo de transmitância térmica para esse fechamento;

(d) a temperatura de globo é pouco indicativa do desconforto causado por radiação, a diferença de temperatura radiante plana é mais adequada para esse fim;

(e) importância da captação de radiação solar, na situação de inverno, através de aberturas voltadas a norte e da inércia térmica da edificação, como estratégias de aquecimento solar passivo;

(f) necessidade de atualização periódica dos agentes em conhecimentos referentes ao desempenho térmico de edificações;

(g) importância do desenvolvimento de projetos que possam ser construídos por etapas, com diretrizes e especificações de melhorias a serem implementadas pelo usuário final em curto, médio e longo prazos; (h) necessidade de definição de diretrizes qualitativas para configuração geral da habitação (cores, posição de aberturas, dispositivos de sombreamento de aberturas, entre outros);

(i) necessidade de normas urbanísticas para a implantação de loteamentos de caráter social com distanciamento mínimo entre unidades, para garantir captação de radiação solar e ventilação natural; e

(j) medições para caracterização do comportamento térmico da edificação (situação de frio e calor) abrangendo no mínimo 7 dias consecutivos e uso de métodos padronizados.

Este estudo buscou contribuir para a melhoria de HIS no Brasil mediante a proposição de parâmetros térmicos que permitam uma avaliação mais integrada do edifício, e não de suas partes tomadas isoladamente, o que poderá levar a soluções inadequadas para alguns problemas ligados ao conforto térmico dos usuários.

\section{Referências}

ASSOCIAÇÃO BRASILEIRA DE NORMAS TÉCNICAS. NBR 15220-1: desempenho térmico de edificações: parte 1: definições, símbolos e unidades. Rio de Janeiro, 2005a.

\section{ASSOCIAÇÃO BRASILEIRA DE NORMAS}

TÉCNICAS. NBR 15220-2: desempenho térmico de edificações: parte 2: métodos de cálculo de transmitância térmica, da capacidade térmica, do atraso térmico e do fator de calor solar de elementos e componentes de edificações. Rio de Janeiro, 2005b.

\section{ASSOCIAÇÃO BRASILEIRA DE NORMAS}

TÉCNICAS. NBR 15220-3: desempenho térmico de edificações: parte 3: zoneamento bioclimático brasileiro e diretrizes construtivas para habitações unifamiliares de interesse social. Rio de Janeiro, 2005c.

\section{ASSOCIAÇÃO BRASILEIRA DE NORMAS}

TÉCNICAS. NBR 15575-1: edifícios

habitacionais de até cinco pavimentos: desempenho: parte 1: requisitos gerais. Rio de Janeiro, 2008a. 
ASSOCIAÇÃO BRASILEIRA DE NORMAS

TÉCNICAS. NBR 15575-4: edifícios

habitacionais de até cinco pavimentos: desempenho parte 4: sistemas de vedações verticais internas e externas. Rio de Janeiro, 2008 b.

\section{ASSOCIAÇÃO BRASILEIRA DE NORMAS}

TÉCNICAS. NBR 15575-5: edifícios

habitacionais de até cinco pavimentos: desempenho: parte 5: requisitos para sistemas de coberturas. Rio de Janeiro, 2008c.

AMERICAN SOCIETY OF HEATING, REFRIGERATING AIR-CONDITIONING ENGINEERS (ASHRAE). Handbook of Fundamentals. New York, 2005.

AROZTEGUI, J. M. Método para Projeto e Avaliação de Pára-Sois Externos, visando à Otimização do seu Desempenho Térmico para um Clima Dado. Porto Alegre: Curso de PósGraduação em Engenharia Civil, 1980. Caderno Técnico.

AROZTEGUI, J. M.; BRIZOLARA, A. Abordagem do Estabelecimento de Exigências de Desempenho Térmico das Paredes Feitas de Concreto de Diversos Tipos, quando Aplicadas à Habitação Popular. Porto Alegre: Curso de Pós-Graduação em Engenharia Civil, 1980. Caderno Técnico.

BARBOSA, M. J. Uma Metodologia para Especificar e Avaliar o Desempenho Térmico de Edificações Residenciais Unifamiliares. 1997. 374 f. Tese (Doutorado em Engenharia de Produção) - Universidade Federal de Santa Catarina, Florianópolis, 1997.

BECKER, M. de F. M. Análise do Desempenho Térmico de uma Habitação Unifamiliar Térrea. 1992. 87 f. Dissertação (Mestrado em Engenharia Civil) - Universidade Federal do Rio Grande do Sul, Porto Alegre, 1992.

BRASIL. Ministério da Agricultura, Pecuária e Abastecimento. Instituto Nacional de Meteorologia. Normais Climatológicas: Porto Alegre - RS. Brasília, DF, 2006. Disponível em: $<$ http://www.inmet.gov.br/clima.php\#>. Acesso em: 05 maio 2006.

FORTES, A. B. Geografia Física do Rio Grande do Sul. Porto Alegre: Globo, 1959.

FROTA, A. B.; SCHIFFER, S. R. Manual de Conforto Térmico. São Paulo: Studio Nobel, 1995.
GIVONI, B. Comfort, Climate Analysis and Building Design Guidelines. Energy and Buildings, v. 18, p. 11-23, 1992.

GIVONI, B. Man, Climate and Architecture. London: Applied Science, 1981.

GOULART, S. Dados Climáticos para Projeto e Avaliação Energética de Edificações para 14 Cidades Brasileiras. Florianópolis: Núcleo de Pesquisa em Construção, UFSC, 1997.

\section{GOULART, S. Thermal Inertia and Natural}

Ventilation: optimization of thermal storage as a cooling technique for residential buildings in Southern Brazil. 2004. 196 f. Thesis (Doctoral) Architectural Association School, Architecture Graduate School, London, 2004.

\section{INTERNATIONAL ORGANIZATION FOR} STANDARDIZATION (ISO). ISO 7726: ergonomics of the thermal environment: instruments for measuring physical quantities. Geneva, 1996.

\section{INTERNATIONAL ORGANIZATION FOR} STANDARDIZATION (ISO). ISO 13788:

hygrothermal performance of building components and building elements: internal surface temperature to avoid critical surface humidity and interstitial condensation: calculation methods. Geneva, 2001

MACHADO, F. P. Contribuição ao Estudo do Clima do Rio Grande do Sul. Rio de Janeiro: IBGE, 1950.

MORELlO, A. Avaliação do Comportamento Térmico do Protótipo Habitacional Alvorada. 2005. 178 f. Dissertação (Mestrado em Engenharia Civil) - Universidade Federal do Rio Grande do Sul, Porto Alegre, 2005.

SATTLER, M. A. Computer-Based Design Techniques for the Thermal Analysis of Low Cost Housing in Brazil, Incorporating the Use of Shading by Trees. 1987. $95 \mathrm{f}$. Thesis (Doctoral in Philosophy) - Faculty of Architectural Studies, Department of Building Science, University of Sheffield, Sheffield, 1987.

SILVA, R. D.; BASSO, A. Avaliação do Conforto Térmico em Habitações de Interesse Social em Madeira. In: ENCONTRO NACIONAL DE TECNOLOGIA DO AMBIENTE CONSTRUIIDO, 9., 2002, Foz do Iguaçu. Anais... Porto Alegre: ANTAC, 2002. p. 213-219. 
TURIK, N. Estabelecimento de Exigências de Desempenho Higrotérmico da Envolvente de Habitações Populares Térreas: estudo aplicado à casa COHAB Tipo RS 16_I.3-42. 1988. 267 f.

Dissertação (Mestrado em Engenharia Civil) Universidade Federal do Rio Grande do Sul, Porto Alegre, 1988. 